\title{
FUNCTIONALS RELATED TO THE DEC INEQUALITY
}

\author{
LudMila NikOlova AND SANJA VAROŠANEC
}

Abstract. We consider the so-called DEC inequality via theory of isotonic linear functionals. The DEC inequality is a refinement of the well-known Cauchy inequality and its well-known particular cases are the Milne and the Callebaut inequalities. We also investigate properties of some functionals which are arised from the DEC inequality.

Mathematics subject classification (2010): 26D15, 26 D99.

Keywords and phrases: The Callebaut inequality, the DEC inequality, isotonic linear functional, mean, the Milne inequality, superadditivity.

\section{REFERENCES}

[1] D. Baleanu, S. D. Purohit, P. Agarwal, On fractional integral inequalities involving hypergeometric operators, Chinese Journal of Mathematics Volume 2014 (2014), Article ID 609476.

[2] W. W. BRECKNER, Stetigkeitsaussagen fur eine Klasse verallgemeinerter konvexer funktionen in topologischen linearen Raumen, Publ. Inst. Math. 23 (1978), 13-20.

[3] M. Bohner, A. Peterson, Dynamic equations on time scales: An introduction with applications, Birkhäuser, Boston, 2001.

[4] D. K. Callebaut, Generalization of the Cauchy-Schwarz inequality, J. Math. Anal. Appl. 12 (1965), 491-494.

[5] D. E. Daykin, C. J. Eliezer And C. Carlitz, Problem 5563, Amer. Math. Monthly, 75 (1968), p. 198 and 76 (1969), 98-100.

[6] S. S. Dragomir, Refinements of the Cauchy-Bunyakovsky-Schwarz inequality for functions of selfadjoint operators in Hilbert spaces, Linear and Multilinear Algebra, 59 (7) (2011), 711-717.

[7] V. S. KiRYAKova, Generalized fractional calculus and applications, Pitman Res. Notes in Math. Ser. 301. Longman - J. Wiley, Harlow - N. York, (1994).

[8] E. A. Milne, Note on Rosseland's integral for the stellar absorption coefficient, Monthly Notices of the Royal Astronomical Society, 85 (1925), 979-984.

[9] D. S. Mitrinović, J. E. PeČArić, A. M. Fink, Classical and New Inequalities in Analysis, Kluwer Academic Publishers, Dordrecht-Boston-London, 1993.

[10] E. Neuman, J. SÁndor, On the Schwab-Borchardt mean, Math. Pannon. 14 (2) (2003), $253-266$.

[11] L. Nikolova, S. VARošAnec, Properties of some functionals associated with h-concave functions with applications on inequalities, J. Inequal. Appl. 2014, 2014:30.

[12] J. E. Pečarić, F. Proschan, Y. L. Tong, Convex Functions, Partial Orderings, and Statistical Applications, Academic Press Inc, Boston, 1992.

[13] S. M. Sitnik, Generalized Young and Cauchy-Bunyakowsky inequalities with applications: a surwey, Advances in Modern Analysis, Mathematical Forum Series, Ed. Yu. F. Korobeinik, A. G. Kursaev, 2009, 221-266.

[14] S. VArošaneC, On h-convexity, J. Math. Anal. Appl. 326 (2007), 303-311.

[15] A. Witkowski, On Seiffert-like means, ArXiv:1209.1244v1 [math.CA] 5 Sep 2013. 